\title{
Tropical sol da liberdade: narrativa pós-traumática, espaço de dor e esquecimento
}

\author{
Tropical sol da liberdade: \\ Post traumatic narrative, space of pain and oblivion \\ Andrea Quilian de VARGAS* \\ Universidade Federal de Santa Maria (UFSM) \\ Rosani UMBACH** \\ Universidade Federal de Santa Maria (FSM)
}

\begin{abstract}
RESUMO: No século XX, regimes como o fascismo, o nazismo, o salazarismo, o franquismo, cada um a seu modo, colocaram em cheque a condição verdadeiramente humana do homem. Através dos relatos das vítimas das catástrofes, nos foi revelada uma realidade antes inimaginável. As sequelas deixadas pelos eventos traumáticos interessaram não somente a médicos e psiquiatras, mas também às ciências sociais, incluindo a Literatura. Entre os livros que versam sobre os horrores das Ditaduras na América Latina, está Tropical sol da liberdade, da escritora brasileira Ana Maria Machado, documento importante de um tempo que não pode ser esquecido. A protagonista do romance, vítima da repressão no Brasil dos anos 60, apresenta características das vítimas das catástrofes estudadas pelas pesquisadoras Griselda Kaufman e Jeanne Marie Gagnebin. Marcada por traços de insegurança, falta de perspectiva, apatia, lapsos de memória e crises de identidade, a personagem nos emociona e convida a repensarmos a nossa história.
\end{abstract}

PALAVRAS-CHAVE: Romance. Memória. Trauma

ABSTRACT: In the XX century, Fascism, Nazism, Salazar, Franco Regimes, each one according to its own rules, cast doubt on the true human condition. Through the report of the victims, it was revealed an unimaginable reality. The consequences left by these traumatic events called the attention of physicians, psychiatrists and also of the social sciences including Literature. Among many works concerning Dictatorship in Latin America, the novel, Tropical Sol da Liberdade by Ana Maria Machado, a Brazilian writer, is an important document from a time that should not be forgotten. The protagonist of this novel is a victim of the repression during the 60's in Brazil. She carries same characteristics observed on victims of catastrophes as studied by the researchers Griselda Kaufman and Jeanne Marie Gagnebin, such as: insecurity, apathy, lack of perspective, memory lapses and identity crises. The protagonist thrills us, leading the reader to rethink and analyze the Brazilian history from this period.

KEYWORDS: Novel. Memory. Trauma

\footnotetext{
* Mestre em Estudos Literários pela Universidade Federal de Santa Maria (UFSM), sob orientação da professora doutora Rosani Umbach, linha de pesquisa Literatura, comparatismo e crítica social. Santa Maria - Rio Grande do Sul. E-mail: andrea.quilian@hotmail.com.

** Professora doutora do programa de Pós-Graduação em Letras do Centro de Artes e Letras, Departamento de Letras Estrangeiras Modernas da Universidade Federal de Santa Maria (UFSM); coordenadora da linha de pesquisa Literatura, comparatismo e crítica social. Santa Maria - Rio Grande do Sul. E-mail: rosani.umbach@ufsm.br.
} 


\section{Introdução: Século XX, culto à barbárie}

$\mathrm{O}$ século $\mathrm{XX}$ foi marcado por uma série de eventos catastróficos para a humanidade. Entre guerras, conflitos, disputas pelo poder e a perda da liberdade, o ser humano, abismado, presenciou o triunfo à barbárie. Nenhum outro intelectual denominou de maneira tão apropriada o século passado quanto Eric Hobsbawm: "Era dos extremos". O Holocausto, na Alemanha, e as ditaduras na América Latina, por seu alto teor traumático, despertaram dúvidas sobre os limites do ser humano, dividido entre lembrar e esquecer os momentos em que quaisquer noções de humanidade foram abandonadas. Sara Kofman (1987, p. 21), em seu pequeno livro Paroles suffoquées, escreveu: "Sobre Auschwitz e depois de Auschwitz, não é possível narração, se por narração entende-se: contar uma história de eventos fazendo sentido". Entretanto, é justamente essa ausência de sentido que motivou as ciências sociais, a Medicina e a Psiquiatria a dedicarem-se ao estudo da narração dos fatos traumáticos, investigando os sintomas psíquicos e as consequências dessas experiências para as vítimas. As artes e a Literatura, como bem sabemos, também abriram espaço para a reflexão artística acerca do evento traumático, pois, como pontua Seligmann-Silva (2008, p. 6), num artigo intitulado Testemunho da Shoah e literatura:

o evento exige ser narrado [...] porque o sobrevivente sente esta necessidade e a sociedade tem um compromisso moral de escutá-lo.[...] porque os crimes devem ser registrados, documentados e a Justiça tem parte essencial no trabalho de luto e de memória.

Neste sentido, a memória funciona como um mecanismo capaz de resgatar e, ao mesmo tempo, libertar a vítima das impossibilidades impostas pelo momento traumático vivido. É com base nas memórias da personagem principal do romance Tropical sol da liberdade, da escritora Ana Maria Machado (2005), que analisaremos, neste trabalho, as consequências psíquicas deixadas pela Ditadura Militar na protagonista, marcada por traços de insegurança, falta de perspectiva, apatia, lapsos de memória e crises de identidade frequentes. Nesta empreitada, buscaremos suporte teórico nos estudos de Griselda Kaufman (1998), Jeanne Marie Gagnebin (2006) e Márcio Seligmann-Silva (1999, 2003, 2008), entre outros.

\section{Por que lembrar?}

O que você disser, não diga duas vezes. Encontrando seu pensamento em outra pessoa: negue-o. Quem não escreveu sua assinatura, quem não deixou retrato

Quem não estava presente, quem nada falou Como poderão apanhá-lo? Apague os rastros!

Cuide, quando pensar em morrer Para que não haja sepultura revelando onde jaz

Com uma clara inscrição a lhe denunciar

E o ano de sua morte a lhe entregar Mais uma vez: Apague os rastros!

(Brecht) 
Jeanne Marie Gagnebin, em Lembrar, escrever, esquecer, questiona: "por que falamos tanto em memória, em conservação, em resgate?" (GAGNEBIN, 2006, p. 39). A escritora se interroga sobre essa vontade de verdade que nos move e crê que tal atitude "remete mais a uma ética da ação presente que a uma problemática da adequação (pretensamente científica) entre 'palavras' e 'fatos"" (GAGNEBIN, 2006, p. 39). Cita Walter Benjamin (apud GAGNEBIN 2006, p. 41), que recusava os ideais da ciência histórica (para ele, burguesa e historicista), que intentava fornecer exatidão sobre o passado. Para o filósofo, "a história é objeto de uma construção cujo lugar não é o tempo homogêneo e vazio, mas aquele preenchido pelo tempo-agora". Dessa forma, Benjamin nega os discursos niveladores e absolutos que se pretendem universais, levando a discussão para o âmbito da historiografia, intentando reflexões no presente.

Os debates em torno da veracidade dos relatos históricos se intensificaram após a Segunda Guerra Mundial, pois segundo Gagnebin (2006, p. 41),

[...] a experiência do horror e da exterminação metódica parece ter provocado um abalo sem precedentes da confiança na ciência e na razão. Essas duas questões são aquelas da escrita da história, em particular seu caráter literário, até mesmo ficcional, e da memória do historiador (de seu grupo de origem, de seus pares, de sua nação), em particular dos liames que a construção da memória histórica mantém com o esquecimento e a denegação.

As investidas no esquecimento e na denegação, mencionadas no trecho acima, foram e são ameaças à escrita da história. Gagnebin (2006) cita a tentativa de apagamento do passado perpetrada pelos nazistas quando se torna claro que os alemães não seriam vencedores. Prisioneiros dos campos de concentração desenterraram seus camaradas mortos (já em decomposição) para que fossem queimados, pois esses não poderiam deixar rastros, câmaras de gás e crematórios de Auschwitz foram explodidos pelo mesmo motivo. Em Os afogados e os sobreviventes, Primo Levi refere-se à vontade dos nazistas em tornar inenarrável a vida nos campos: inenarrável pela falta de provas, inenarrável pelo teor absurdo dos relatos dos sobreviventes, que veriam anulada sua credibilidade até junto aos seus familiares, que se negariam a ouvir ou acreditar em tamanha barbárie. Contudo, para que o horror não seja esquecido ou negligenciado, Gagnebin (2006, p.47) atribui ao historiador uma tarefa deveras difícil:

Ele [o historiador] precisa transmitir o inenarrável, manter viva a memória dos sem-nome, ser fiel aos mortos que não puderam ser enterrados [..]. Tarefa altamente política: lutar contra o esquecimento e a denegação é também lutar contra a repetição do horror [...]. Tarefa igualmente ética e, num sentido amplo, especificamente psíquico: as palavras do historiador ajudam a enterrar os mortos do passado e a cavar um túmulo para aqueles que dele foram privados. Trabalho de luto que nos deve ajudar, nós, os vivos, a nos lembrarmos dos mortos para melhor viver hoje. Assim, a preocupação com a verdade do passado se completa na exigência de um presente que, também, possa ser verdadeiro.

A importância do historiador no relato do episódio traumático talvez resida no fato de que a vítima frequentemente se encontra impossibilitada de narrar os acontecimentos, já que o trauma, segundo Freud, promove uma ruptura entre o sujeito e os mecanismos simbólicos, especialmente a linguagem. A historiografia, nesse veio, "deixa de ser a narração de uma história de sucessos (e do sucesso) e explode em fragmentos e estilhaçosvale dizer: em ruínas" (SELIGMANN-SILVA, 2003, p. 390). Não só o historiador, mas também o poeta, o narrador tem o dever de não deixar o passado cair no esquecimento. 
No Brasil, as tentativas de apagamento da memória também se fizeram presentes nos depoimentos dos militares integrantes do chamado "esquema de defesa" do país contra o suposto avanço comunista. Não são raros os depoimentos em que os militares envolvidos no Golpe de 64 declaram que a intervenção violenta do governo foi necessária e que só ocorreu porque houve resistência por parte do povo. Também há relatos que negam as práticas de tortura e mortes. O general Leônidas Pires Gonçalves, integrante do gabinete militar de Castelo Branco, quando questionado sobre os órgãos de repressão, declara: "Desafio agora alguém a provar que era inocente e que tenha sido torturado, ou que tenha sofrido qualquer restrição maior do que as técnicas nos prometiam, que era o isolamento" (DINES, 2001, p. 354). Subentende-se, pelo discurso do militar, que a inocência livrava o interrogado da tortura. Mas quem decidia quem era inocente? Sobre remexer a história, o general Leônidas demonstrou visível desconforto:

Então, fazem umas pesquisas históricas e remexem em coisas do passado muito unilateralmente. Não gosto de ver isso. Então, vamos mexer, mas mexer para quê? [...] Tenho dúvidas sobre a validade de remexer essas coisas do passado, mesmo no sentido histórico, isso não presta serviço nenhum (DINES, 2001, p. 356).

Evidencia-se, dessa forma, o desinteresse das Forças Armadas em que os fatos da Ditadura Militar no Brasil sejam vasculhados. Há, ao contrário, uma intenção de apagamento do fato da memória coletiva.

Opondo-se a essas tentativas de apagamento da memória, de algumas décadas para cá, o interesse pela reconstrução da memória individual e coletiva tem levado as ciências sociais, as artes e a Literatura a dedicarem-se ao estudo da narração dos fatos traumáticos. Tal investida tem como objetivo tratar os traumas das vítimas das catástrofes, reintegrá-las à sociedade.

Para Márcio Seligmann-Silva (1999, p. 40), somente a arte pode dar conta de enfrentar o desafio de representar o indizível:

O testemunho se coloca desde o início sobre o signo de sua simultânea necessidade e impossibilidade. Testemunha-se um excesso de realidade e o próprio testemunho enquanto narração testemunha uma falta: a cisão entre a linguagem e o evento, a impossibilidade de recobrir o vivido (real) com o verbal. O dado inimaginável da experiência concentracionária desconstrói o maquinário da linguagem. Essa linguagem entravada, por outro lado, só pode enfrentar o real equipada com a própria imaginação: por assim dizer, só com a arte a intraduzibilidade pode ser desafiada - mas nunca totalmente submetida.

O testemunho através da obra literária, para Seligmann-Silva (2003, p. 78), pode ser caracterizado como

uma atividade elementar, no sentido de que dela depende a sobrevida daquele que volta do Lager (campo de concentração) ou de outra situação radical de violência que implica esta necessidade, ou seja, que desencadeia esta carência absoluta de narrar. [...] A narrativa teria [...] esse desafio de estabelecer uma ponte com "os outros", de conseguir resgatar o sobrevivente do sítio da outridade, de romper com os muros do Lager. A narrativa seria a picareta que poderia ajudar a derrubar este muro. [...] Narrar o trauma, portanto, tem em primeiro lugar este sentido primário de renascer. 
Isso não significa recriar uma história, mas costurar os fragmentos, os estilhaços do passado com os quais a história oficial não sabe o que fazer, como o sofrimento, aqueles que não têm nome, os que foram mortos e sepultados ainda em vida. A história, nesse sentido, não trata das feridas, não oferece ao morto uma sepultura digna. A Literatura, dita testemunhal, talvez o faça, pois encena, de modo particular, a relação da Literatura com a realidade a que se refere.

\section{Quem são as testemunhas?}

Sobre o termo testemunha, cabem aqui algumas ponderações. Segundo Gagnebin (2006, p. 57),

[...] testemunha também seria aquele que não vai embora, que consegue ouvir a narração insuportável do outro, e que aceita que suas palavras levem adiante, como num revezamento, a história do outro: não por culpabilidade ou por compaixão, mas porque somente a transmissão simbólica, assumida apesar e por causa do sofrimento indizível, somente essa retomada reflexiva do passado pode nos ajudar a não repeti-lo infinitamente, mas a ousar esboçar uma outra história, a inventar o presente.

Nesse sentido, não podemos considerar testemunha somente quem foi preso, torturado de maneira direta, mas também quem ouviu, quem se solidarizou, quem não foi embora.

A esse respeito, Susana Griselda Kaufman (1998, p. 15), num artigo intitulado Sobre violência social, trauma y memória, pontua:

Las diferentes formas e intensidad del sufrimiento de las víctimas directas y de quien las rodean han llevado muchas veces a conflictos acerca de la legitimidad de los discursos en relación con la lucha por la reconstrucción de la memoria. ¿Quién determina cuál es lo discurso adecuado? ¿Es la condición de víctima directa la única que legitima el discurso? ¿Quienes no lo son, están excluidos?

A autora questiona, nesse fragmento, a relevância do testemunho da vítima direta sobre a indireta e sugere que, embarcar nessa esteira de pensamento, excluir quem não foi diretamente afetado pelo evento traumático, só reforçaria a diferença da própria vítima em relação aos outros, quando tudo o que se quer, na verdade, é reintegrá-la. Márcio Seligmann-Silva (2003, p. 372 - 373) afirma que:

\footnotetext{
A literatura de testemunho é mais do que um gênero: é uma face da literatura que vem à tona na nossa época de catástrofe e faz com que toda a história da literatura [...] seja revista a partir do questionamento da sua relação e do seu compromisso com o "real". [...] esse real não deve ser confundido com a realidade tal como ela era pensada e pressuposta pelo romance realista e naturalista: o "real" que nos interessa aqui deve ser compreendido na chave freudiana do trauma, de um evento que resiste à representação.
}

Nesses termos, testemunhar não deve ser entendido somente como um ato individual de superação das sequelas deixadas pelo evento traumático, mas é um compromisso social e humanitário de denúncia e repúdio à barbárie.

Foi justamente nesse contexto inenarrável que, segundo Alfredo Bosi (2002, p. 125), surgiu a chamada Literatura de resistência: 
Foi um tempo excepcional, um tempo quente de união de forças populares e intelectuais progressistas. Tempo que perdurou na memória dos narradores do imediato pós-guerra, e que produziu o cerne da chamada literatura de resistência.

A partir daí, a Literatura estaria a serviço da luta contra os regimes totalitários e contra o aprisionamento físico ou emocional do homem. Essa nova tendência encheu a sociedade de esperanças no poder transformador da narrativa, que fez emergir tudo que foi calado por medo, angústia, incapacidade. A Literatura, nessa esteira, tornou-se o lugar das verdades mais doloridas e traumáticas. Segundo Bosi (1995, p. 1), a escrita da memória dos fatos históricos que se transmuta em fazer literário, "com o compromisso de representar a 'realidade objetiva' é a literatura de testemunho. Nem pura ficção, nem pura historiografia, testemunho". Testemunhar, contudo, nem sempre é tarefa fácil: primeiro, porque a testemunha esteve no cerne do conflito, direta ou indiretamente, o que pode tê-la impedido de visualizar a situação de maneira objetiva; segundo, porque a violência do acontecido pode ter deixado marcas traumáticas profundas.

\section{0 trauma}

De algumas décadas para cá, o interesse pela reconstrução das memórias individuais e coletivas tem como objetivo não só aprofundar o estudo das causas, mas também tratar as vítimas das catástrofes. O estudo do trauma, inicialmente, esteve ligado à Medicina, à Psiquiatria, à Psicanálise. O contato com vítimas de guerras, conflitos e ditaduras, marcas do século XX, representou um marco importante para o desenvolvimento das pesquisas que intencionavam a cura para o trauma, mas também serviu para mostrar o quão "indizível” foi esse tempo. Os traumatizados, nesses termos, são o sintoma dessa história, mas todos estamos envolvidos nela.

A noção de trauma descreve uma ferida, uma ruptura que desconstrói e desestrutura o sujeito, tornando-o, em muitos casos, incapaz de falar sobre o evento traumático. $\mathrm{O}$ indivíduo não entende o trauma como algo natural, como parte de si, mas como algo externo, difícil de ser articulado. A memória, segundo Griselda Kaufman (1998, p. 3), desempenha um papel fundamental na tentativa de dar um novo sentido à vida.

\footnotetext{
El acceso a la temporalidad de la memoria evoca recuerdos y actualiza marcas que, al repetirse o ser puestos en pensamientos actuales, se resignifican, son desagregados, aparecen o se olvidan, dando lugar a nuevas formas de presencia o de ausencia. [...] La memoria puede organizar su rememoración, parecer inmutable frente al paso del tiempo, ser borrada, reaparecer, resurgir, ser objeto de contradicciones, actualizarse en huellas, recuerdos y repeticiones.
}

Nesses termos, o complexo trabalho da memória consiste em reabrir o ocultado, o esquecido, mas também manter no esquecimento o intolerável para que haja um equilíbrio psíquico. Em situações de catástrofe, a memória é fragmentada, bloqueada, dependendo do teor da violência sofrida pela vítima.

Esses efeitos do trauma sobre as vítimas serão explorados neste trabalho, que tem como objeto de estudo a obra Tropical sol da liberdade, de Ana Maria Machado, que versa sobre o período da Ditadura Militar no Brasil. 


\section{0 corpo machucado}

O texto é narrado em terceira pessoa e nos conta a vida de uma mulher que vivenciou os anos de chumbo e deles não saiu ilesa. A construção da personagem Lena, jornalista, irmã de um líder estudantil, concentra características das vítimas dos regimes totalitários que possuem o corpo como um de seus alicerces, mas também o portador das marcas da violência, seja física ou psicológica. Após a decretação do AI 5, em especial, a personagem viveu dias de tormento, em que sentimentos confusos, intensos, ameaçadores, a acompanhavam constantemente. Entre o medo, a raiva e a insegurança, Lena viu-se obrigada a deixar o país, sob a ameaça de ser presa. Essa violência simbólica, a retirada de um indivíduo de seu território, deixou marcas indeléveis na personagem. De volta ao Brasil e com sérios problemas neurológicos que a impediam de escrever, a protagonista ainda quebra o dedão do pé e vai para a casa da mãe, numa tentativa de reconstruir-se física e emocionalmente, ou, quiçá, para buscar no passado alguma forma de olhar o futuro, agora tão turvo. Segundo Griselda Kaufman (1998), nessas ocasiões, o sujeito perde o equilíbrio e a segurança com relação à vida, vendo-se impossibilitado de reagir, como na seguinte passagem do romance:

O futuro era cheio de limites. Não criar nem procriar. Não admira que, no presente, esbarrasse nas paredes e tivesse dificuldade de se manter de pé. Ou que ficasse mergulhando para o avesso do seu tecido, agulha tentando alinhavar tramas dispersas, procurando resgatar no passado algum ponto de apoio que lhe desse firmeza. Mesmo que fosse só para aproveitar as sobras e chegar a uma colcha de retalhos feita em casa (MACHADO, 2005, p. 50-51).

A simbologia presente na construção do corpo de Lena, um corpo machucado, desestabilizado, parece estar atrelada aos sintomas apresentados pelas vítimas de eventos traumáticos, como pontua Kaufman (1998, p.5):

Lo traumático bajo condiciones de violencia social lleva a una pérdida de equilibrio y seguridad y a vivencias de desamparo equiparables a la desproteción e inmadurez originarias del infante humano, también a estados de obnubilación, falta de conciencia, pérdida de significaciones y de explicación de lo ocurrido.

Seguindo por esse viés, cabe lembrar que não são raras as vezes em que Lena acorda no chão, sem saber como foi parar ali. Machado não propõe, na diegese da narrativa, uma explicação para a incidência desses lapsos, o que nos leva a pensar na possibilidade da autora ter elaborado a personagem com vistas aos sintomas do trauma nas vítimas dos regimes autoritários. Frases sem nexo, palavras soltas, silêncios, tudo são sintomas de distúrbios pós-traumáticos, de acordo com Griselda Kaufman (1998). A impossibilidade de escrever, de rememorar, colocar no papel a sua história, também nos leva a crer na hipótese de que a caracterização da protagonista também configure, no romance, denúncia desse outro lado da Ditadura: o trauma que ela provoca. Sobre essa limitação, Lena se questiona:

Será que a doença era só uma somatização de todos os impedimentos e obstáculos que sabia e previa? Será que era medo, preguiça, cagaço? [...] E se alguma coisa no mundo interior dela estivesse conseguindo enganar até a ele [o médico] e a ela mesma? (MACHADO, 2005, p. 52). 
Ana Maria Machado construiu um romance de denúncia e subversão à história oficial, tendo como protagonista uma personagem incapaz, no presente da narrativa, de fazê-lo. Entretanto, observa-se o temor de Lena diante da possibilidade de que pessoas e fatos que marcaram esse período conturbado da história brasileira sejam esquecidos: "Não ia esquecer nunca e não entendia como tanta gente esqueceu tão depressa. Lembrava cada detalhe" (MACHADO, 2005, p. 70). É por isso que ela estava empenhada em escrever uma peça de teatro que concedesse voz à sua experiência. Quem a incentivava nesta empreitada era o velho poeta Luis Cesário, que, juntamente com sua mulher Carlota, lhe passavam lições de vida e informações relevantes. Lena lembra com ternura as conversas, nas quais o poeta afirmava a necessidade de uma reflexão moral profunda na sociedade, clamando por um espírito ético que distinguisse a civilização da barbárie, o conceito do bem, a valorização suprema da dignidade do homem. Lena também admirava o poder que acompanhava as palavras da amiga Carlota, "que ficavam contidas e recolhidas, maturando no silêncio e, de repente, se manifestavam plenas e carregadas de magnetismo"; considerava-a uma pessoa "inteiramente soldada ao seu presente e ao futuro do seu país e da gente de todos os países" (MACHADO, 2005 p. 101). Apesar de sentir-se incapaz de escrever, a protagonista vê a necessidade de fazê-lo para não sucumbir diante de "um país desnorteado, que perdia suas referências" (MACHADO, 2005, p. 100).

A incapacidade de Lena para dar o seu testemunho pode ser compreendida como um sintoma de quem esteve muito próximo do conflito, fato que talvez a impeça de gerar um testemunho lúcido e íntegro. Através de um enredo baseado nas impossibilidades dessa personagem, entretanto, a escritora Ana Maria Machado denunciou o regime militar brasileiro.

Tropical sol da liberdade privilegia, dessa forma, o tão laborioso ato de escrever. Um dos princípios da composição da narrativa é a reflexão acerca do processo de produção de ficção, pois Lena deseja contar a sua história, escrever uma peça de teatro. A protagonista problematiza também as motivações, os mitos, as técnicas que envolvem o fazer literário, conferindo um teor metaficcional à obra. Isso representa um ataque à distância instituída, até o século XIX, entre escritor e leitor. Segundo Theodor Adorno (2003), no século XX, o romance passa a ser construído de maneira que se encurtem as distâncias estéticas, ou seja, o leitor é convidado a conhecer os liames da produção da obra, livrando-se de uma atitude apenas contemplativa. Segundo Adorno (2003), a tomada de consciência em relação à necessidade dessa postura mais ativa do leitor exige que se busquem novas formas de representação estética e, assim, "[...] a abolição da distância é um mandamento da própria forma (ADORNO, 2003, p. 63)”. Nesse sentido, percebe-se que não foi por acaso que Ana Maria Machado criou uma obra metaficcional, mas para incitar o leitor a participar da trama.

\section{Considerações finais}

À Literatura cabe, sempre, transgredir, resistir, denunciar. Escrever, nesse sentido, não é um compromisso somente com a palavra, mas com a sociedade. Não é com armas que o escritor luta, mas com as palavras. Na esperança de expor o drama, tentar ordenar os fragmentos, contar no palco a trajetória de uma mulher na periferia dos acontecimentos, Lena luta contra suas limitações e seus traumas. Num artigo intitulado Narrar o traumaA questão dos testemunhos de catástrofes históricas, Márcio Seligmann-Silva (2008, p. 70), afirma que "a imaginação é chamada como arma que deve vir em auxílio do simbólico para enfrentar o buraco negro do real do trauma. O trauma encontra na imaginação um meio para sua narração". Ana Maria Machado (2005), em Tropical sol da liberdade, nos 
oferece uma oportunidade de adentrarmos, através das memórias de Lena, nesse vazio provocado pelo trauma, quebrando o pacto de silêncio tão bem aceito pelo povo brasileiro que, segundo Maria Rita Hehl (2010, p. 237),

[...] costuma "deixar barato" o resgate das grandes injustiças de sua história para não manchar sua reputação de "último povo feliz" do planeta. Mas que preço caro pagamos por essa felicidade para inglês ver! [...] Não passamos nada a limpo, não elaboramos nossos traumas nem valorizamos nossas conquistas. Por isso mesmo nós, brasileiros, não nos reconhecemos no discurso que produzimos [...] Por essa razão, estamos sempre em dívida para com uma identidade perdida.

Marcada na carne pela Ditadura, a protagonista tem consciência de que só poderá seguir adiante, redescobrir sua identidade, quando enterrar o passado. Entre brancos, lapsos, tonturas, inseguranças, palavras desconexas, dificuldade de ficar de pé, ela prossegue. Não nos é revelado, ao final do romance, o destino dessa mulher. É provável que oferecer-nos um "final feliz" não tenha sido o objetivo de Ana Maria Machado ao escrever o romance. O que fica claro nas páginas de Tropical sol da liberdade é que, somente através das tentativas de desencapsular o trauma da memória, Lena conseguirá atribuir um novo significado para sua vida. Através da escritura, poderá ser possível levar o passado adiante, descolori-lo, aliviar o peso da carga da memória. No passado, encriptado nas fotos, reportagens de jornais e revistas, cartas, diários guardados pela mãe da protagonista, registros de um tempo que ainda atormenta, está o sentido de sua existência e a chave da cripta onde Lena se encontra enclausurada: ela mesma.

\section{REFERÊNCIAS}

ADORNO, T. W. Posição do narrador no romance contemporâneo: notas de literatura I. São Paulo: Duas Cidades, Editora 34, 2003.

BOSI, A. Literatura e resistência. São Paulo: Companhia das Letras, 2002.

BOSI, A. A escrita do testemunho em Memórias do Cárcere. Estudos Avançados, v. 9, n. 23, jan./abr 1995, p. 309-322.

DINES, A. (Org.). Histórias do poder: 100 anos de política no Brasil. 2. ed. São Paulo: Ed. 34, 2001.

GAGNEBIN, J. M. Lembrar Escrever Esquecer. São Paulo: Ed. 34, 2006.

KAUFMAN, G. Sobre violência social, trauma y memoria. In: SEMINARIO MEMORIA COLECTIVA Y REPRESIÓN - SSRC, 1998. Disponível em: $<$ http://www.cholonautas.edu.pe/modulo/upload/GKauffman.pdf $>$. Acesso em: $04 \mathrm{dez}$. 2011.

KEHL, M. R. Ressentimento e rememoração. Disponível em: <http://webcache.googleusercontent.com/search?q=cache:4t9vexeLuC4J:www.oretratodob rasil.com.br/reportagem/65/pdf/10.pdf+Tortura+e+sintoma+social+\%22Maria+Rita+Kehl \%22\&hl=pt-BR \&gl=br>. Acesso em: 10 jan. 2011.

KOFMAN, S. Paroles suffoquées. Paris: Galilée Éditions, 1987.

MACHADO, A. M. Tropical sol da liberdade. Rio de Janeiro: Nova Fronteira, 2005.

SELIGMANN-SILVA, M. Narrar o trauma: a questão dos testemunhos de catástrofes históricas. Psic. Clin., v. 20., n. 1, p. 65-82, Rio de Janeiro, 2008. 
SELIGMANN-SILVA, M. História, memória, literatura: o testemunho na Era das Catástrofes (Org.). Campinas, São Paulo: Editora da UNICAMP, 2003.

SELIGMANN-SILVA, M. A literatura do trauma. Revista Cult, São Paulo, n. 23, p. 40, jun. 1999.

SELIGMANN-SILVA, M. Testemunho da Shoah e literatura. Revista Eletrônica Rumo à tolerância. FFLCH-IEL-UNICAMP, 2008, p.16. Disponível em: <http://www.rumoatolerancia.fflch.usp.br/files/active/0/aula_8.pdf>. Acesso em: $10 \mathrm{dez}$. 2011.

Recebido em: 14 de janeiro de 2012.

Aprovado em: 08 de abril de 2012. 